\title{
POPULATION GENETICS OF THE TREE HOLE MOSQUITO AEDES TRISERIATUS: NO CORRELATION BETWEEN EST-6 AND LARVAL HABITAT
}

\author{
T. C. MATTHEWS \\ Vector Biology Laboratory, Department of Biology, University of Notre Dame, \\ Notre Dame, Indiana 46556, U.S.A.
}

Received 15.vii.83

\section{INTRODUCTION}

After a decade and a half of study and debate, the controversy brought about by the discovery of extensive genetic variation in natural populations remains unresolved. A few studies have presented evidence for the selective advantage of some allozymes in experimental populations (Hickey, 1977; Georghiou and Pasteur, 1978; Cavener and Clegg, 1981; Wilson et al., 1981), while others have found correlations between specific enzyme phenotypes and environmental variables (Johnson, 1971; Schopf and Gooch, 1971; Hedrick et al., 1976; Nelson and Hedgecock, 1980; Nadeau and Baccus, 1981).

One study linking allele frequencies with an environmental variable was that of Saul et al. (1978) which found a significant correlation between larval habitat and the frequency of esterase alleles in populations of the tree-hole mosquito, Aedes triseriatus. Frequencies of two out of 14 Est-6 alleles, $0 \cdot 87$ and 0.90 , in mosquitoes from oak forests were approximatèly equal, whereas in mosquitoes from beech forests, the 0.90 allele was almost twice as common as the 0.87 allele. In both oak forests and beech forests, however, the sum of the frequencies of the two alleles was approximately equal $(0.55)$, with the remaining frequencies distributed among the other alleles. The difference between pooled oak and pooled beech was highly significant $(p \ll 0.001)$. These patterns were found in all eight oak and six beech populations, and held over a north-south gradient of $100 \mathrm{~km}$ in northern Indiana and southern Michigan, U.S.A., as well as in two disjunct populations from Wisconsin and Maryland.

The differences in allele frequencies between oak and beech mosquitoes were nebulously ascribed to "coarse-tuned" selection which maintained the frequencies of the two alleles, and to "fine-tuned" selection which kept the sum of their frequencies constant. Proximity of, and migration between woodlots was ruled out as a cause of similarity of allele frequencies in beech/oak populations because of the disjunct distribution of the two ecotypes, and because "the ecology of Aedes triseriatus is especially suitable for eliminating the effect of migration".

Their study generated much interest and their conclusions were important to future genetic, ecological, and epidemiological studies of $A$. triseriatus. The present study was undertaken in hopes of further clarifying the postulated association between larval habitat and Est-6. 


\section{MethodS AND MATERIALS}

\section{(i) Sampling technique}

Collections of $A$. triseriatus from ten localities (five from "oak" forests and five from "beech" forests) were obtained by removing larvae from basal tree-holes and rearing them to adulthood in the laboratory. A minimum of 5 tree-holes from each woodlot were sampled. Samples were taken randomly, that is, in predominantly oak forests, samples were not restricted to oak tree-holes, and likewise in predominantly beech forests, samples were not restricted to beech tree-holes. Six of the 10 populations were the same as those previously studied by Saul et al.

\section{(ii) Electrophoresis and allozyme resolution}

The basic electrophoretic procedures used in this study were similar to those used in the previous study. Mosquitoes were homogenised and centrifuged, and the resulting supernatant applied to 5 per cent polyacrylamide gels and electrophoresed. As in the earlier study, diethyl- $p$-nitrophenyl phosphate was used to inhibit all extraneous esterases. Because of the extreme variability of Est-6 and the difficulty of differentiating the numerous allozymes, several additional steps were incorporated into this study which significantly increased the accuracy and precision of identifying electromorphs:

(a) Six control mosquitoes, which were all homozygous for the allele designated $1 \cdot 000$, were strategically placed on each 36 -slot gel. As a result, no individual sample was more than three slots from a control, thus making it possible to resolve small but significant differences between allozyme bands.

(b) Electromorphs were measured to the nearest $0.5 \mathrm{~mm}$ from the origin using the adjacent controls to insure consistent scoring across the gel.

(c) Paired sets of gels were run for each population to check repeatability from run to run.

\section{(iii) Statistical analysis}

The Biosys-1 program of Swofford and Selander (1981) was used to analyze the data and to generate dendrograms based on Nei's (1978) genetic distance. The G-test (Sokal and Rohlf, 1969) was used to test for geneticecological associations.

\section{Results}

Twenty-one different electromorphs, including several which were rare, were identified at the Est-6 locus. Frequencies for 15 allelic classes, after grouping rare alleles, are presented in table 1 , along with statistical tests for pooled oak and beech data. The G-statistic obtained by comparing pooled beech and pooled oak data is not significant $(p \simeq 0 \cdot 14)$, indicating that no statistical correlation exists between habitat type and allele frequencies at the Est- 6 locus. The random placement of oak and beech types in the UPGMA cluster analysis (fig. 1) provides additional evidence of the 


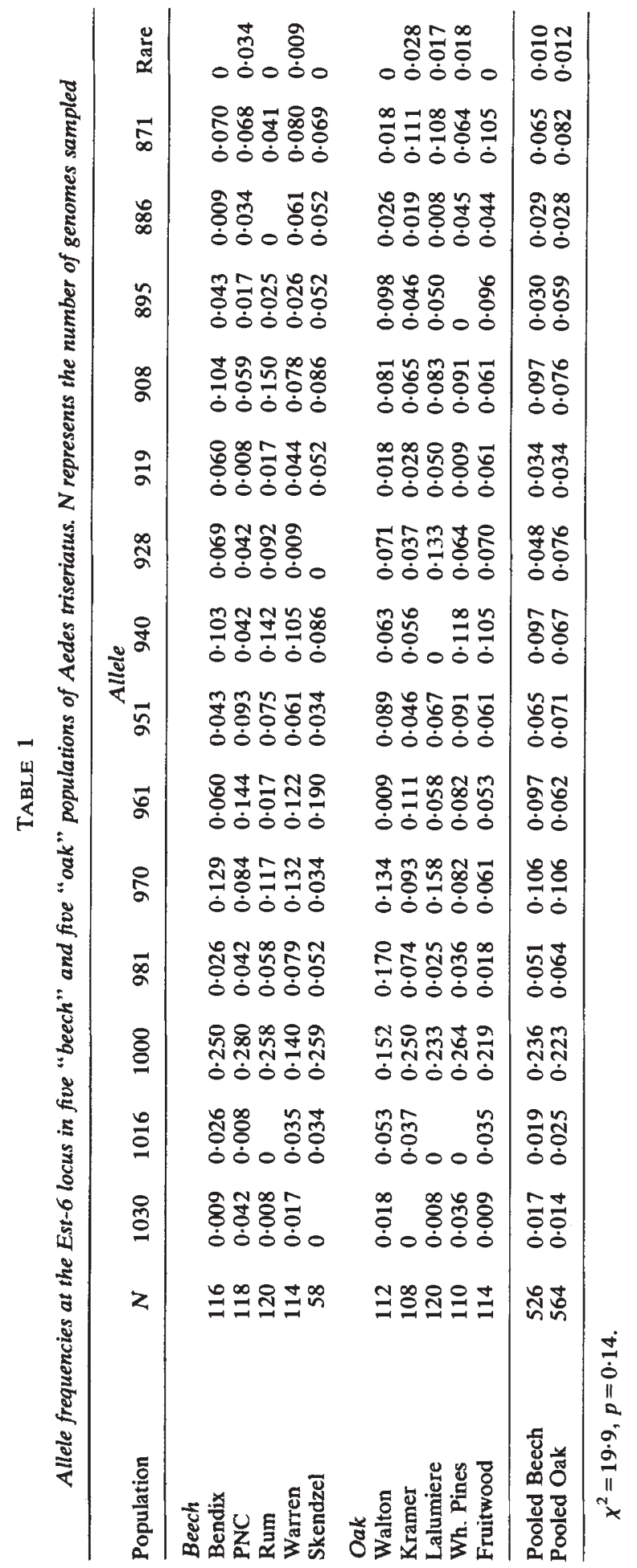




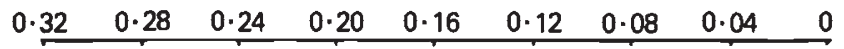
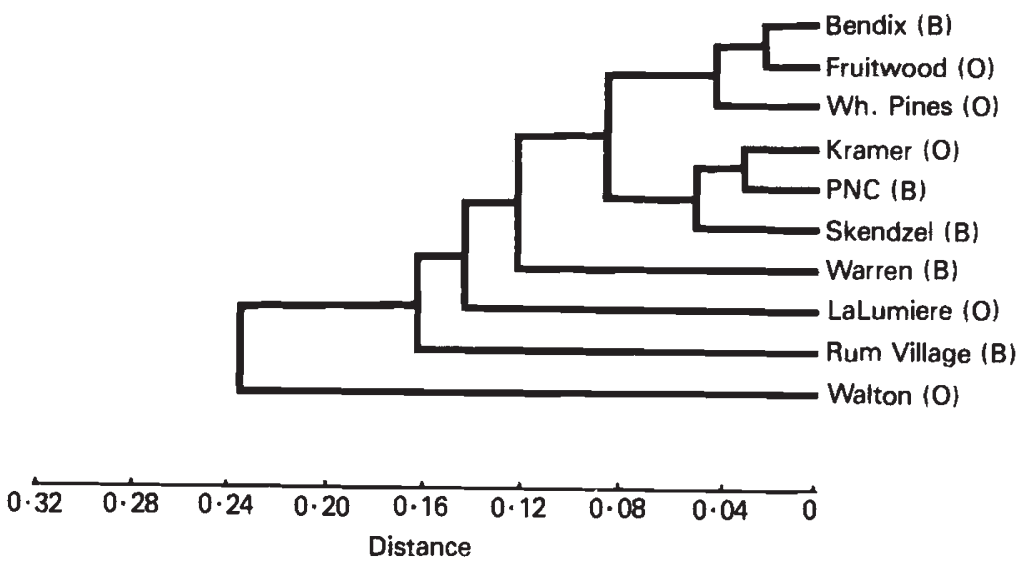

FIG. 1. UPGMA cluster analysis of ten populations of Aedes triseriatus based on a matrix of Nei's genetic distances for Est-6. The five beech and five oak populations are designated as " $B$ " and " $O$ ".

independence of allele frequencies and larval habitat. The average genetic distance for beech-beech, oak-oak, and beech-oak comparisons were $0 \cdot 153$, $0 \cdot 132$, and $0 \cdot 139$ respectively.

\section{Discussion}

Although it would have been very desirable, comparison of Saul's data, especially the 0.97 and 0.90 alleles, with my data was not possible on an allele for allele basis because (1) different controls were used in the two studies, and (2) greater resolution in this study made Saul's 0.87 and 0.90 alleles "composites" of several of mine ( 21 vs. 14 total alleles). However, this would not affect the detection of genetic-ecological correlations had they been present. None were detected. In the ensuing discussion, I will present evidence which supports my findings that no correlation exists between Est- 6 and habitat.

One of the main arguments proposed by Saul et al., to explain their results was that "oak and beech stands were not found in mixed stands but rather in separate isolated ones". Closer observation shows that most woodlots in this region are mixed associations of oak and hickory or beech and maple with other minor species interspersed. However, it is not unusual to find combinations of these species, including oak and beech, in the same forest. Rum Village and Bendix Park, classified as "beech", also have many maples and several oaks with tree-holes harbouring immature $A$. triseriatus. Walton and Fruitwood, classified as "oak" are mixed assemblages of oak, maple, and hickory. Of the woodlots surveyed in my study, only Kramer and Whispering Pines were predominantly oak, and Warren predominantly beech. If selection favours certain allele frequencies in beech tree-holes, and other frequencies in oak tree-holes, as suggested by Saul et al., then one would expect still different selection pressures in maple, hickory, and other tree-hole habitats. The actual ecological situation is not as simple as 
depicted in their study. The presence of different types of larval habitat in the same forest, with each forest having its own peculiar composition does not support an "either-or" type of selection and the establishment of simple allele frequency patterns such as described in their study.

The second major supposition of the Saul study was that A. triseriatus habitats were "ecological islands" between which there was no gene flow. This assertion stems from a demographic study by Sinsko (1976) which failed to detect movement of marked mosquitoes between two adjoining woodlots. Extrapolating from Sinsko's study to a general statement that $\boldsymbol{A}$. triseriatus populations are completely isolated is probably erroneous. From a genetic standpoint, undetectable movement between populations could have significant effects. Some idea of how small migration rates might be while remaining genetically important can be obtained by solving for $m$ in the equation, $d=2\left((p)(1-p) /\left(4 N_{e} m+1\right)\right)^{1 / 2}$ (Lewontin, 1974), where $p$ is the average allele frequency and $d$ the absolute difference in allele frequencies between two groups. A conservative estimate of $N_{e}$ based on Sinsko's study is on the order of 1000 . Using this value and $d$ and $p$ derived from data in Matthews and Craig (1980), migration rates ranging from approximately 0.01 to 0.05 , or roughly 10 to 50 migrants per generation were obtained. Rates this small could easily go undetected in conventional mark-release-recapture studies, but still contribute to genetic homogeneity in $A$. triseriatus populations.

There is considerable evidence to suggest that this has in fact happened. In an electrophoretic study based on 18 enzyme loci, Matthews and Craig found that these populations share more than 99 per cent of their genetic variation $(I=0.994)$. The average genetic similarity for beech-oak comparisons $(0.993)$ were almost identical to beech-beech $(0.994)$ and oak-oak $(0.994)$ comparisons. Even more compelling evidence of the absence of differentiation is provided by statistical analyses of pooled oak and beech data. Not one of 14 polymorphic loci deviated significantly from independence (table 2). As might have been predicted from the large similarity

TABLE 2

Test for association of allele frequencies and treehole habitat (pooled oak vs. pooled beech) at 14 variable loci in natural populations of Aedes triseriatus

\begin{tabular}{|c|c|c|c|}
\hline Locus & G-Value & $\mathrm{df}$ & $p$ \\
\hline Gpi & 6.6 & 3 & 0.09 \\
\hline$H b d$ & $2 \cdot 8$ & 4 & 0.60 \\
\hline $\mathrm{Me}$ & $7 \cdot 6$ & 3 & 0.06 \\
\hline$I d h-1$ & 0.7 & 2 & $0 \cdot 70$ \\
\hline$I d h-2$ & 1.4 & 4 & 0.85 \\
\hline Gpd & $3 \cdot 6$ & 3 & 0.30 \\
\hline Odh & $4 \cdot 4$ & 5 & 0.50 \\
\hline Pgm & $6 \cdot 0$ & 4 & $0 \cdot 20$ \\
\hline$H k-4$ & $1 \cdot 8$ & 2 & 0.40 \\
\hline Fum & $2 \cdot 8$ & 2 & 0.25 \\
\hline$A k$ & $4 \cdot 2$ & 2 & $0 \cdot 12$ \\
\hline Sod-3 & 0.6 & 2 & 0.75 \\
\hline$M d h$ & $7 \cdot 4$ & 4 & 0.12 \\
\hline$P g d$ & $2 \cdot 8$ & 1 & $0 \cdot 10$ \\
\hline
\end{tabular}


values, $F$-statistics for the 18 loci in Matthews and Craig's study were comparatively small $(F=0.014)$ and homogeneous $(0<F<0.039)$. These results can be explained in two ways, neither of which is mutually exclusive: (1) all $\boldsymbol{A}$. triseriatus populations are subjected to similar environments (or at least respond to them genetically as if they were similar) which results in general adaptation, and (2) genetic similarity of these populations is due to their breeding structure (of which migration is a significant component). Neither scenario, however, is compatible with the assumptions and conclusions of Saul et al., which envisioned selection as specialised with respect to larval habitat, and which excluded migration as an important aspect of A. triseriatus demography. The fact that the $F$-statistic for Est-6 is identical to the average $F$-value for the 18 other loci $(0 \cdot 014)$, makes the argument for ecological isolation and selective differentiation even less plausible. Conversely, the case for migration is considerably strengthened by Slatkin's (1981) study which presented a model for determining the level of gene flow based on electrophoretic data. He found that the "conditional average frequency" of an allele, $\bar{p}(i)$, was dependent on migration rates, but nearly independent of selection and mutation, and thus could be used to estimate migration whether or not selection was operating. Plotting $p(i)$ against $u$ for $A$. triseriatus (where $i$ is the number of demes in which an allele is present) generates a curve similar to Slatkin's simulation using a migration rate of $0 \cdot 1$ (fig. 2). Species with migration rates of this order of magnitude (e.g., Drosophila pseudoobscura, $D$. willistoni, and apparently $A$. triseriatus) are referred to as "high migration species".

In conclusion, the evidence presented supports the view that $\boldsymbol{A}$. triseriatus populations are not differentiated at the Est-6 locus as a result of isolation and differential selection in oak vs. beech habitats. The genetic homogeneity found in these populations appears to result in large part from gene flow between them.

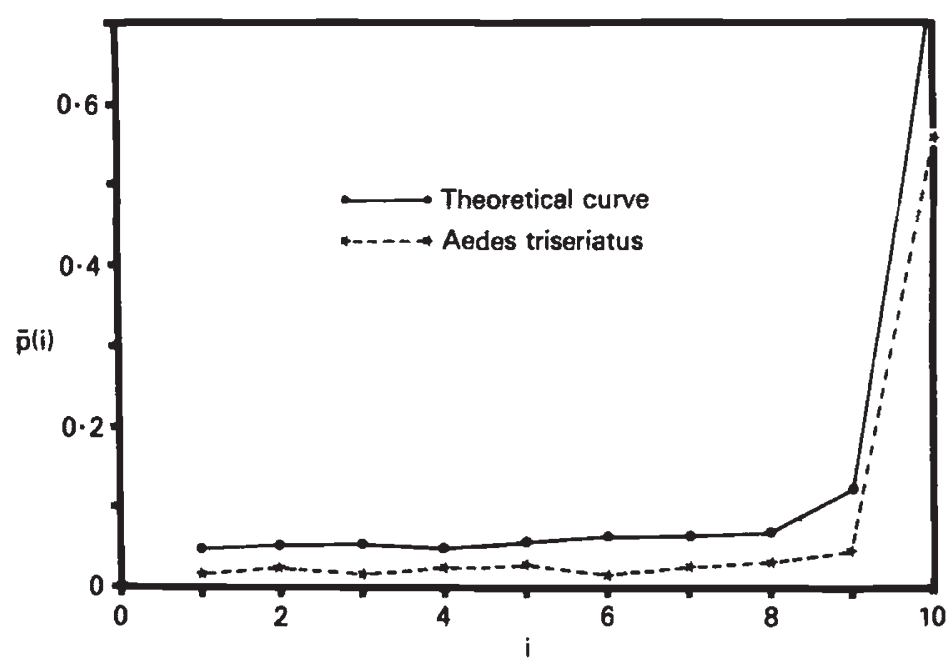

FiG. 2. Graphs of conditional average allele frequency, $\bar{p}(i)$ vs. occupancy number, $i$. The curve for Ae. triseriatus is based on 18 loci in 10 populations. The theoretical curve is based on a migration rate of $0 \cdot 1$ (Slatkin, 1981, fig. 2a). 
Acknowledgments. The support and encouragement of Dr George B. Craig, Jr., and helpful discussions with Dr L. E. Munstermann throughout this study, and the advice of Dr Dorothy Pashley in reviewing the manuscript are gratefully acknowledged. This study was supported by NIH Research Grant No. AI-02753.

\section{REFERENCES}

CAVENER, D. R. AND CLEGG, M. T. 1981. Multigenic response to ethanol in Drosophila melanogaster. Evolution, 35, 1, 1-10.

GEORGHIOU, G. P. AND PASTEUR, N. 1978. Electrophoretic esterase patterns in insectisideresistant and susceptible mosquitoes. J. Econ. Entomol., 71, 201-205.

HEDRICK, P. W., GINEVAN, M. E. AND EWING, E. P. 1976. Genetic polymorphism in heterogeneous environments. Ann. Rev. Ecol. Syst., 7, 1-32.

HICKEY, D. A. 1977. Selection for amylase allozymes in Drosophila melanogaster. Evolution, $31,800-804$.

JOHNSON, M. S. 1971. Adaptive lactate dehydrogenase variation in the crested blenny, Anoplorchus. Heredity, 27, 205-226.

LEWONTIN, R. C. 1974. The Genetic Basis of Evolutionary Change. Columbia University Press, New York.

MATTHEWS, T. C. AND CRAIG, G. B. JR. 1980. Genetic heterozygosity in natural populations of the tree-hole mosquito Aedes triseriatus. Ann. Entomol. Soc. Amer., 73, 739-743.

NADEAU, J. H. AND BACCUS, R. 1981. Selection components of four allozymes in natural populations of Peromyscus maniculatus. Evolution, 35, 11-20.

NEIL, M. 1978. Estimation of average heterozygosity and genetic distance from a small number of individuals. Genetics, 89, 583-590.

NELSON, K. AND HEDGECOCK, D. 1980. Enzyme polymorphism and adaptive strategy in the decapod Crustacea. Am. Nat., 116, 238-280.

SAUL, S. H., SINSKO, M. J., GRIMSTAD, P. R. AND CRAIG, G. B. JR. 1978. Population genetics of the mosquito Aedes triseriatus: Genetic-ecological correlation at an esterase locus. Am. Nat., 112, 333-339.

SCHOPF, T. J. AND GOOCH, J. L. 1971. Gene frequencies in a marine ectoproct. A cline in natural populations related to sea temperature. Evolution, 25, 286-289.

SINSKO, M. J. 1976. Dynamics of an isolated population of Aedes triseriatus (Diptera: Culicidae). Ph.D. Dissertation, University of Notre Dame, IN.

SLATKIN, M. 1981. Estimating levels of gene flow in natural populations. Genetics, 99, 323-335.

SOKAL, R. R. AND ROHLF, F. J. 1969. Biometry. W. H. Freeman and Co., San Francisco.

SWOFFORD, D. L. AND SELANDER, R. B. 1981. Biosys-1: A FORTRAN program for the comprehensive analysis of electrophoretic data in population genetics and systematics. J. Heredity, 72, 281-283.

WILSON, S. R., OAKESHOTT, J. G., GIBSON, J. B. AND ANDERSON, P. R. 1982. Measuring selection coefficients affecting the alcohol dehydrogenase polymorphism in Drosophila melanogaster. Genetics, 100, 113-126. 